In Crescendo. Institucional. 2016; 7(1): 157-161

Fecha de recepción: 6 de mayo de 2016

Fecha de aceptación: 17 de mayo de 2016

\title{
REFLEXIONES SOBRE LA ESCRITURA ACADÉMICA Y CIENTÍFICA
}

\author{
REFLECTIONS ON ACADEMIC AND SCIENTIFIC WRITING
}

Alberto Carrasco Torres*

RESUMEN

Es scribir para comunicar el producto de una investigación ha sido siempre un "dolor de cabeza" para los académicos. Desde los temores que se tiene por lo escrito hasta los mitos que se asumen para descalificarse como buenos escritores. Se plantea entonces una reflexión que sugiere un repensar en el enfoque comunicativo de la escritura y acabar con las falsas creencias que asumen los académicos con respecto a las condiciones que deben poseer para considerarse escritores. El propósito comunicativo de la escritura es asumirla de manera clara y efectiva. La única condición que debe poseer un escritor académico científico es tener algo que comunicar. Esto se convierte, finalmente, en un acicate para escribir inexorablemente.

Palabras clave: escritura académica, escritura científica, redacción

\begin{abstract}
Write to communicate the product of research has always been a "headache" for academics. From the fears that we have by writing to the myths that are assumed to disqualify themselves as good writers. Arises a reflection that suggests a rethink in the communicative approach of writing and do away with the false beliefs that assume the academics with regard to the conditions that must possess to be considered writers. The communicative purpose of writing is to assume it in a clear and effective manner. The only condition that must have a scientific academic writer is to have something to communicate. Finally, it becomes an incentive to write inexorably.
\end{abstract}

Keywords: academic writing, scientific writing, writing 


\section{INTRODUCCIÓN}

Quienes estamos vinculados a la comunidad científica —investigadores, profesores universitarios, académicos - desarrollamos investigaciones cuyos resultados contribuyen a la solución de problemas de la sociedad. Cierto es lo que en su libro señalan Bayarre y Hosford (2011): "La investigación científica es aquel proceso de carácter creativo que pretende encontrar respuestas a problemas trascendentes mediante la construcción teórica del objeto de investigación, o mediante la introducción, innovación o creación de tecnologías" (p. 67). Sin embargo, comunicar los resultados de las investigaciones realizadas es siempre un asunto postergado.

El presente artículo tiene como propósito ser un motivador para que los académicos consideren el hecho de publicar en una revista científica como un deber y una obligación para los investigadores y todos los actores vinculados a las ciencias, incluyendo las ciencias sociales, que han sido por largo tiempo excluidas de esta categoría. Que lo asuman como un proceso sencillo que necesita solo el atreverse a escribir. Que dejen falsas creencias que los estigmatizan como malos escritores y que definen a la escritura académica y científica como un arte de genios superdotados.

Para romper con estos temores que rodean el mito de la escritura académica y científica se plantean dos razones básicas: el propósito de la escritura y las condiciones que debe poseer un escritor: ¿Cuáles son las características que posee una buena escritura? ¿Cuáles son las cualidades que debe poseer un escritor académico y científico?

A lo largo de esta reflexión sincera se responde a las interrogantes planteadas y se espera que los académicos empiecen ya con su labor natural de escribir para publicar.

\section{DESARROLLO TEMÁTICO}

\section{La escritura académica y científica}

Es interesante recordar lo que en el siglo XIII escribió San Buenaventura, ilustrado santo de la Iglesia Católica, respecto a la labor de la escritura (referido por Teberosky, 2007):

Un hombre puede escribir los libros de otros, sin agregar ni cambiar nada, caso en el que se llama simplemente "escriba". Otro hombre escribe obras ajenas con adiciones que no son suyas, siendo llamado "compilador". Otro escribe obras tanto suyas como ajenas y juntando las suyas a título de explicación, se le llama "comentador". Otro escribe su obra tanto como la de otros, pero da lugar principal a la suya, juntando las restantes con el propósito de confirmación; ese hombre es llamado "escritor". (p. 17)

Para iniciarnos en la escritura académica y científica debemos repensar el enfoque que tenemos respecto de la escritura en general, reconsiderar el proceso de escribir y vencer algunos temores que podamos tener por lo escrito.

Empecemos por responder la siguiente pregunta: ¿Qué es lo que hace que una escritura sea buena? 
El primer elemento que hace que una escritura sea buena es su propósito comunicativo: comunicar de manera clara y efectiva. Y es aún más importante en la escritura académica, porque su objetivo es conseguir que los resultados de la tarea científica lleguen a otros científicos, a los políticos y, a veces, incluso, hasta el público en general. Se trata de lograr expresar, a través de la redacción, las ideas con claridad y eficacia.

En segundo lugar, está este otro elemento de la buena escritura, y es lo que todo el mundo asocia: la buena escritura es hermosa, es elegante.

Y es precisamente lo que sucede con una gran cantidad de académicos que se sientan a escribir: se preocupan por este segundo elemento. Están preocupados por sonar inteligentes o sonar elegantes. Dedican mucho tiempo a centrarse en ese detalle que se olvidan de que simplemente tienen que transmitir sus ideas con claridad y eficacia. Este mito los conduce a todo tipo de problemas en la escritura.

Lo que debemos hacer es mantener el enfoque, el propósito: comunicar con claridad y eficacia.

Hay que preocuparse menos por la parte elegante y el estilo. Para escribir con claridad solo se necesita tener algo que decir y el pensamiento claro. En la medida en que los académicos y científicos tenemos algo que expresar, también tenemos un pensamiento claro. Por lo tanto, esta parte realmente no debería ser intimidante.

Recordemos que la escritura es un proceso que recorremos en tres tramos, en tres fases: la planificación, la textualización y la revisión. La parte elegante y el estilo no brotan en un primer borrador. Lo elegante y el estilo en la escritura ocurren en la revisión. Incluso para los escritores profesionales y literatos. Tener a la vista una revista o una novela, significa que ha sido filtrada a través de una buena edición. No está como en el primer borrador. Se ha pulido muchas veces por varios especialistas, correctores y editores.

Por consiguiente, no debemos siquiera preocuparnos por lo elocuente ni lo elegante cuando se está escribiendo el primer borrador. En este nivel, la tarea es conseguir que las ideas lleguen de forma clara, lógica y eficiente.

\section{El escritor académico y científico}

Respondamos ahora una segunda pregunta: ¿qué es lo que hace a un buen escritor?

Una de las creencias que se asocia con los buenos escritores es pensar que para ser uno de ellos, se debe tener algún tipo de talento innato. Y muchos de los académicos y científicos creen que no nacieron con el gen de la escritura, sino que "por el contrario", con el gen de la matemática.

Se cree también que se necesitan años de clases de lingüística y redacción, respetar a la RAE sin cuestión ni rebeldía, para convertirse en un buen escritor. Se piensa que se necesita algún tipo de naturaleza artística; incluso que se necesita la influencia del alcohol y las drogas o tal vez algún tipo de inspiración divina o una especie de musa. 
Todas esas condiciones se asocian con el buen escritor y muchos académicos creen en esta necesidad, pero en realidad, esto no es cierto.

Lo único que se necesita para ser un buen escritor es tener algo que decir, que tenga que comunicarse inexorablemente. Algo que apasiona. Sé que suena un poco trivial, pero cuántas veces he tenido a algún colega que se sienta en mi oficina, cuando estoy revisando su producción escrita y, ante un párrafo ininteligible, le pregunto qué es lo que estaba tratando de decir. Me mira y dice "bueno, no estoy muy seguro de lo que estaba tratando de decir en ese párrafo. Lo sé, y por eso es un párrafo confuso". Con la práctica, con la escritura constante, se convertirá en un escritor que examina y revisa su obra y para quien "la habilidad de detectar lo superfluo y lo que puede cambiarse, corregirse, ampliarse y, especialmente, eliminarse, resulta esencial" (Cabero, 1948, p. 10).

En la redacción científica debemos tener muy claro, en primer lugar, qué es lo que se está tratando de decir. Luego, por supuesto, se necesita el pensamiento lógico y claro. Ser capaz de argumentar de una manera lógica. La mayoría de los académicos y científicos sabemos categóricamente que tenemos ambas cosas. Que tenemos algo que decir y que tenemos el pensamiento lógico. No hay atajo alguno entonces, empecemos a escribir, a comunicar nuestras investigaciones, a publicarlas.

Algo adicional, el escritor académico y científico, el docente vinculado a esta tarea, debe exigir la publicación de sus artículos. Tal como señala Fernández-Quijada (2009): "Los autores, precisamente, también deben ser exigentes con el trato y difusión que se dé a su trabajo, y están en su derecho de exigir una política clara de valoración del mismo a través de publicaciones" (p. 8).

\section{CONCLUSIONES}

1. Existe un abismo entre las investigaciones realizadas por académicos y científicos, y las publicaciones de los resultados obtenidos en dicha tarea.

2. Un primer impedimento es la falsa concepción que se tiene de la escritura académica y científica, que se aleja de su verdadero propósito comunicativo: informar con claridad y eficacia.

3. La segunda falsa idea es asociar la escritura con un arte hermoso y elegante, dejando de lado el fundamental propósito de comunicar. En la revisión y edición se retoca el texto por especialistas, tales como correctores y editores.

4. Luego está presente el mito del escritor superdotado de talento innato, que hace que el académico se sienta limitado para escribir. En realidad, lo único que se necesita es tener algo que comunicar, y los académicos tienen mucho que decir.

5. No existe impedimento, entonces, para comunicar. Es una exigencia, un deber hacer llegar nuestros resultados a la comunidad científica, a la clase política, a la población. 


\section{REFERENCIAS BIBLIOGRÁFICAS}

Bayarre Vea, H. y Hosford Saing, R. (2011). Métodos y técnicas aplicadas a la investigación en atención primaria de salud. La Habana: Editorial Ciencias Médicas.

Cabero, A. (1948). Recuerdos de don Pedro Aguirre Cerda. Santiago de Chile: Nascimento.

Fernández-Quijada, D. (2008). Revistas científicas e índices de impacto: A propósito de "Hacer saber". Área abierta, 20.

Teberosky, A. (2007). El texto académico. En Castelló M. (2007). Escribir y comunicarse en contextos académicos y científicos. Conocimientos y estrategias (pp. 17-46). Barcelona: Graó, col. Crítica y fundamentos. 